\title{
Financial Coordination and Income Distribution of Agricultural Supply Chain
}

\author{
Leilei Zhang, Honglian Guo* \\ Beijing Wuzi University, Beijing 101149, China \\ *Corresponding author: Honglian Guo, zhangleilei_819@163.com
}

\begin{abstract}
The agriculture field is a fundamental industry which supports the rapid development of the nation's economy. However, credit constraints faced by farmers have restricted the modernization in the agricultural industry. The agricultural supply chain finance is effective in promoting rural industrial revitalization and agricultural modernization, which is of great significance to the transformation and development of rural economy and agriculture in China. In this paper, the financial coordination model in agricultural supply chain is constructed, and the income distribution model of Shapley value method is introduced. The results showed that the agricultural supply chain finance can significantly improve the income of the participants in the agricultural industrial chain and verify the economic feasibility of agricultural supply chain finance.
\end{abstract}

Keywords: Agriculture; Supply chain finance; Income distribution

Publication date: June 2021; Online publication: June 30, 2021

\section{Introduction}

It is believed that agricultural supply chain finance refers to a systematic solution that focuses on the core enterprises of agricultural characteristics and valuable agricultural products which bundles the interests of upstream and downstream small and medium-sized enterprises (SMEs), farmers, or consumers; hence, designing rational and systematic financial products to meet the financial needs of all the participants in the supply chain, as well as to promote the overall coordination of the agricultural supply chain operation. ${ }^{[1]}$ Agricultural supply chain finance targets the credit status of the whole supply chain. Relying on core enterprises and real trades of specific products improve the credit ratings of SMEs and farmers while reducing financing costs as well as the risks. Hence, it is conducive to the development of agricultural financial services. ${ }^{[2]}$

At present, the research on supply chain finance in the local academic circle is extensive and increasing. However, the research on its application in the agricultural industry is still incomplete. The existing research primarily focus on the background, operation mode, risk control, prevention, poverty reduction mechanism, and so on of the agricultural supply chain finance. Hence, in this paper, the financial coordination model of agricultural supply chain is constructed, and the income distribution model of Shapley value method is introduced to analyze the income of each participant in the agricultural supply chain finance; thereby, discussing the economic feasibility of agricultural supply chain finance.

\section{Operation Process of Agricultural Supply Chain Finance}

The operation of the agricultural supply chain financial model in relation to farmers, agricultural enterprises, and financial institutions is shown in the following figure: 
Operation flow chart of agricultural supply chain financial model

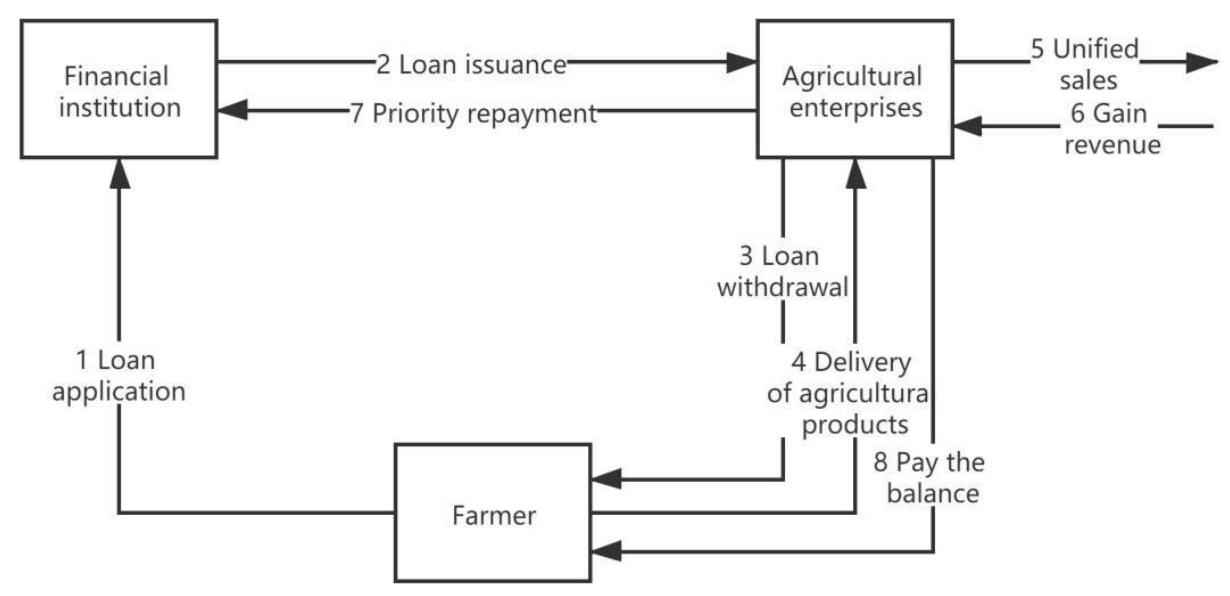

In this model, farmers would apply for loans from financial institutions. As the main body, agricultural enterprises would issue loans in batches after the commencement of agricultural production in order to meet the capital needs of the production process. When the agricultural products have matured, farmers would then supply their products to agricultural enterprises for unified sales. Subsequently, the agricultural enterprises would hand over the revenue made to agricultural cooperatives. These cooperatives function to distribute the remaining balance to the farmers after settling loan repayments to the financial institutions. In this model, the involvement of agricultural cooperatives promoted the assembling of farmers from all over and attained the effect of risk sharing. To a certain extent, the credit guarantee of agricultural enterprises would help to alleviate the difficulties faced by farmers and their costly loans.

\section{Model Building}

\subsection{Supply chain coordination model}

Basic assumptions:

(1) The agricultural supply chain finance is assumed to be operating around a single agricultural product for one cycle and the supply chain only involves one agricultural enterprise and one farmer.

(2) The output function of the farmer is assumed to be $y=y_{0}+a I^{b},(a>0,0<b<1)$, whereby $y_{0}$ is the original output of the farmer without any financial support from financial institutions, $I$ is the amount of loans obtained by the farmer, and $a, b$ reflects the industrial progress rate of the farmer in terms of capital utilization and production efficiency.

(3) The purchase price of agricultural products by the agricultural enterprise is assumed to be $p_{0}$ and the sales price is $p_{1}$. Under the financial model of agricultural supply chain, agricultural enterprises need to bear certain risks in providing credit guarantee for farmers whereby the coefficient of the guarantee cost is assumed to be $\alpha$.

(4) The loan interest rate of financial institutions is assumed to be $\beta$ and the coefficient of the loan cost is assumed as $\gamma$.

Based on the above assumptions, these are derived:

The income function of the farmer:

$U_{1}=p_{0} y-I \beta=p_{0}\left(y_{0}+a I^{b}\right)-I \beta$

The income function of the agricultural enterprise:

$U_{2}=\left(p-p_{0}\right) y-I \alpha=\left(p-p_{0}\right)\left(y_{0}+a I^{b}\right)-I \alpha$ 
The income function of the financial institution:

$U_{3}=I \beta-I \gamma$

The overall benefits of the supply chain:

$U=U_{1}+U_{2}+U_{3}=p\left(y_{0}+a I^{b}\right)-I \alpha-I \gamma$

\subsubsection{Centralized decision-making}

Under centralized decision-making, the farmer, agricultural enterprise, and financial institution would pursue the highest overall interests in the supply chain and mutually decide the loan amount.

Overall benefits of supply chain:

$U=U_{1}+U_{2}+U_{3}=p\left(y_{0}+a I^{b}\right)-I \alpha-I \gamma$

Make: $\frac{d U}{d I}=p a b I^{b-1}-\alpha-\gamma=0$

Availableness: $I^{*}=\left(\frac{\alpha+\gamma}{p a b}\right)^{\frac{1}{b-1}}$

\subsubsection{Decentralized decision-making}

(1) Optimal loan amount of the farmer

The income of the farmer:

$U_{1}=p_{0}\left(y_{0}+a I^{b}\right)-I \beta$

Make: $\frac{d U_{1}}{d I}=p_{0} a b I^{b-1}-\beta=0$

Availableness: $I_{1}^{*}=\left(\frac{\beta}{p_{0} a b}\right)^{\frac{1}{b-1}}$

(2) Optimal secured loan amount of the agricultural enterprise

The income of the agricultural enterprise:

$U_{2}=\left(p-p_{0}\right)\left(y_{0}+a I^{b}\right)-I \alpha$

Make: $\frac{d U_{2}}{d I}=\left(p-p_{0}\right) a b I^{b-1}-\alpha=0$

Availableness: $I_{2}^{*}=\left[\frac{\alpha}{\left(p-p_{0}\right) a b}\right]^{\frac{1}{b-1}}$

(3) Optimal lending amount of the bank

The bank's income:

$U_{3}=I \beta-I \gamma$

If $\beta>\gamma, U_{3}$ is the increasing function of $I$.

If $\beta=\gamma, U_{3}=0$

If $\beta<\gamma, U_{3}$ is the decreasing function of $I$. 


\subsubsection{Supply chain coordination}

Make: $I^{*}=I^{1}=I^{2},\left(\frac{\alpha+\gamma}{p a b}\right)^{\frac{1}{b-1}}=\left(\frac{\beta}{p_{0} a b}\right)^{\frac{1}{b-1}}=\left[\frac{\alpha}{\left(p-p_{0}\right) a b}\right]^{\frac{1}{b-1}}$

Substituting into the original formula:

$$
\begin{aligned}
& U^{*}=p y_{0}+p a\left(\frac{\alpha+\gamma}{p a b}\right)^{\frac{b}{b-1}}-(\alpha+\gamma)\left(\frac{\alpha+\gamma}{p a b}\right)^{\frac{1}{b-1}} \\
& U_{1}^{*}=p_{0} y_{0}+p_{0} a\left(\frac{\alpha+\gamma}{p a b}\right)^{\frac{b}{b-1}}-\beta\left(\frac{\alpha+\gamma}{p a b}\right)^{\frac{1}{b-1}} \\
& U_{2}^{*}=\left(p-p_{0}\right) y_{0}+a\left(p-p_{0}\right)\left(\frac{\alpha+\gamma}{p a b}\right)^{\frac{b}{b-1}}-\alpha\left(\frac{\alpha+\gamma}{p a b}\right)^{\frac{1}{b-1}} \\
& U_{3}^{*}=(\beta-\gamma)\left(\frac{\alpha+\gamma}{p a b}\right)^{\frac{1}{b-1}}
\end{aligned}
$$

\subsection{Income distribution model}

\subsubsection{Distribution strategy based on Shapley value method}

The general model of Shapley value method is as below:

There are $n$ members in alliance $I$, whereby, $I=\{1,2, \cdots, n\}$. For any subset $s \subseteq I$ of $I$, there is a real number $v(s)$ corresponding to it, indicating the benefits of cooperative alliance $s . v(s)$ satisfies the following conditions:

(1) $v(\phi)=0$

(2) $v\left(s_{1} \cup s_{2}\right) \geq v\left(s_{1}\right)+v\left(s_{2}\right),\left(s_{1} \cap s_{2}=\phi, s_{1} \subseteq I, s_{2} \subseteq I\right)$

$v(s)$ is a characteristic function defined on $I$. Set $[I, v]$ represents the cooperative problem of $n$ agents. $\varphi_{i}(v)$ represents the income value allocated by member $i$ from the maximum income $v(I)$ of the alliance. The cooperative allocation strategy is as follows:

(3) $\varphi(v)=\left\{\varphi_{1}(v), \varphi_{2}(v), \cdots, \varphi_{n}(v)\right\}$

(4) $\varphi_{i}(v)=\sum_{s \subset S_{i}} w(|s|)[v(s)-v(s \backslash i)], i=1,2, \cdots, n$

In which $|s|$ is the number of enterprises in the subset, $w(|s|)=\frac{(n-|s|) \cdot(|s|-1) !}{n !}$ is the weighting factor, and $S_{i}$ is the set composed of all subsets including member $i$ in $I$.

\subsubsection{Model assumptions}

The model assumptions are as below:

(1) In the interest alliance of the farmer, agricultural enterprise, and financial institution, if the farmer does not participate, agricultural enterprise will lose their product source while the financial institution will lose their customer. Therefore, the farmer would get a small amount of income from 
independent operation. The income $R_{2}$ from independent operation of the enterprise, the income $R_{3}$ from independent operation of the financial institution, and the income $R_{23}$ from cooperation between the agricultural enterprise and financial institution are all 0 .

(2) The income that the farmer would obtain from operating alone: $R_{1}=p_{0} y_{0}$

(3) The benefits that the farmer and agricultural enterprise would obtain from cooperation: $R_{12}=p y_{0}$

(4) The income from cooperation between the farmer and financial institution: $R_{13}=p_{0}\left(y_{0}+a I^{b}\right)-I \gamma$

(5) Benefits from tripartite cooperation among the farmer, agricultural enterprise, and financial institution: $R_{123}=U=p\left(y_{0}+a I^{b}\right)-I \alpha-I \gamma$

(6) In the process of income distribution, the loan amount can maximize the supply chain income whereby: $I=I^{*}=\left(\frac{\alpha+\gamma}{p a b}\right)^{\frac{1}{b-1}}$

Based on the above assumptions, the income of each participant in agricultural supply chain finance is calculated as below:

\begin{tabular}{|c|c|c|c|c|}
\hline Allocation Model & Farmer & $\begin{array}{c}\text { Farmer and } \\
\text { agricultural } \\
\text { enterprise }\end{array}$ & $\begin{array}{c}\text { Farmer and } \\
\text { financial institution }\end{array}$ & $\begin{array}{c}\text { Farmer, agricultural } \\
\text { enterprise, and } \\
\text { financial institution }\end{array}$ \\
\hline$v(s)$ & $R_{1}$ & $R_{12}$ & $R_{13}$ & $R_{123}$ \\
\hline$v(s \backslash i)$ & 0 & 0 & 0 & 0 \\
\hline$v(s)-v(s \backslash i)$ & $R_{1}$ & $R_{12}$ & $R_{13}$ & $R_{123}$ \\
\hline$|s|$ & 1 & 2 & $\frac{1}{6}$ & $\frac{1}{3}$ \\
\hline$w(|s|)$ & $\frac{1}{3}$ & $\frac{1}{6}$ & $\frac{1}{6} R_{13}$ & $\frac{1}{3} R_{123}$ \\
\hline$w(|s|)[v(s)-v(s \backslash i)]$ & $\frac{1}{3} R_{1}$ & $\frac{1}{6} R_{12}$ & $\frac{1}{3} R_{1}+\frac{1}{6} R_{12}+\frac{1}{6} R_{13}+\frac{1}{3} R_{123}$ & \\
\hline$\varphi_{1}(v)$ & & \multicolumn{2}{c}{} \\
\hline
\end{tabular}

The available income of the farmer:

$\varphi_{1}(v)=\frac{1}{2} y_{0}\left(p+p_{0}\right)+a\left(\frac{p_{0}}{6}+\frac{p}{3}\right)\left(\frac{\alpha+\gamma}{p a b}\right)^{\frac{b}{b-1}}-\left(\frac{\gamma}{2}+\frac{\alpha}{3}\right)\left(\frac{\alpha+\gamma}{p a b}\right)^{\frac{1}{b-1}}$

The available income of the agricultural enterprise:

$\varphi_{2}(v)=\frac{1}{2} y_{0}\left(p-p_{0}\right)+\frac{1}{3} a\left(p-p_{0}\right)\left(\frac{\alpha+\gamma}{p a b}\right)^{\frac{b}{b-1}}-\frac{1}{3} \alpha\left(\frac{\alpha+\gamma}{p a b}\right)^{\frac{1}{b-1}}$

The available income of the financial institution:

$\varphi_{3}(v)=a\left(\frac{p_{0}}{6}+\frac{p}{3}\right)\left(\frac{\alpha+\gamma}{p a b}\right)^{\frac{b}{b-1}}-\left(\frac{\alpha}{3}+\frac{\gamma}{2}\right)\left(\frac{\alpha+\gamma}{p a b}\right)^{\frac{1}{b-1}}$ 


\subsection{Numerical simulation}

According to the optimal benefits of each participant in the first coordination model, and the benefits of each party in the second revenue distribution model, a numerical analysis is carried out. The basic parameters are as follows:

\begin{tabular}{l|l|l|l|l|l|l|l}
\hline$p_{0}$ & $p$ & $y_{0}$ & $a$ & $b$ & $\alpha$ & $\beta$ & $\gamma$ \\
\hline 10 & 12 & 1000 & 10 & 0.5 & 0.01 & 0.05 & 0.05 \\
\hline
\end{tabular}

\subsubsection{Scenario 1: Traditional circulation mode of agricultural products}

Under the traditional circulation mode of agricultural products, financial institutions did not participate. Considering the output of farmers is $y_{0}$ without financial support, agricultural enterprises bought agricultural products from farmers at a price of $p_{0}$, and then sold them to the market at a price of $p$. In this scenario, the benefits of all parties are as follows:

Income of farmers: $\pi_{1}=p_{0} y_{0}=10000$

Income of agricultural enterprises: $\pi_{2}=\left(p-p_{0}\right) y_{0}=2000$

Financial institutions did not participate; hence, the income is 0 .

Overall benefits of supply chain: $\pi=p y_{0}=12000$

\subsubsection{Scenario 2: Agricultural supply chain financial model without income coordination}

In the second scenario, financial institutions participated to provide farmers with a loan amount of $I^{*}$, loan interest rate of $\beta$ and a loan cost of $\gamma$. With financial support, farmers expanded their production scale, and the output increased whereby the output was $y=y_{0}+a I^{b}$. Agricultural enterprises also bought agricultural products from farmers at a price of $p_{0}$ and sold them to the market at a price of $p$. However, this time, agricultural enterprises provided loan guarantees for farmers. Considering the risks and other factors, agricultural enterprises have certain loan guarantee costs with a cost coefficient of $\alpha$. According to the values brought in by $U^{*}, U_{1}^{*}, U_{2}^{*}$ and $U_{3}^{*}$ in the coordination model:

Income of farmers:

$U_{1}^{*}=p_{0} y_{0}+p_{0} a\left(\frac{\alpha+\gamma}{p a b}\right)^{\frac{b}{b-1}}-\beta\left(\frac{\alpha+\gamma}{p a b}\right)^{\frac{1}{b-1}}=60000$

Income of agricultural enterprises:

$U_{2}^{*}=\left(p-p_{0}\right) y_{0}+a\left(p-p_{0}\right)\left(\frac{\alpha+\gamma}{p a b}\right)^{\frac{b}{b-1}}-\alpha\left(\frac{\alpha+\gamma}{p a b}\right)^{\frac{1}{b-1}}=12000$

Income of financial institutions:

$U_{3}^{*}=(\beta-\gamma)\left(\frac{\alpha+\gamma}{p a b}\right)^{\frac{1}{b-1}}=0$

Total benefits of supply chain:

$U^{*}=p y_{0}+p a\left(\frac{\alpha+\gamma}{p a b}\right)^{\frac{b}{b-1}}-(\alpha+\gamma)\left(\frac{\alpha+\gamma}{p a b}\right)^{\frac{1}{b-1}}=72000$ 


\subsubsection{Scenario 3: Financial model of agricultural supply chain with income coordination}

Scenario 3 introduces the Shapley value method income distribution model based on scenario 2 and rationalized the income distribution of each participant. According to the values brought in by $\varphi_{1}(v)$, $\varphi_{2}(v)$, and $\varphi_{3}(v)$ in the distribution model:

Income of farmers:

$$
\varphi_{1}(v)=\frac{1}{2} y_{0}\left(p+p_{0}\right)+a\left(\frac{p_{0}}{6}+\frac{p}{3}\right)\left(\frac{\alpha+\gamma}{p a b}\right)^{\frac{b}{b-1}}-\left(\frac{\gamma}{2}+\frac{\alpha}{3}\right)\left(\frac{\alpha+\gamma}{p a b}\right)^{\frac{1}{b-1}}=39333.3
$$

Income of agricultural enterprises:

$$
\varphi_{2}(v)=\frac{1}{2} y_{0}\left(p-p_{0}\right)+\frac{1}{3} a\left(p-p_{0}\right)\left(\frac{\alpha+\gamma}{p a b}\right)^{\frac{b}{b-1}}-\frac{1}{3} \alpha\left(\frac{\alpha+\gamma}{p a b}\right)^{\frac{1}{b-1}}=4333.3
$$

Income of financial institutions:

$$
\varphi_{3}(v)=a\left(\frac{p_{0}}{6}+\frac{p}{3}\right)\left(\frac{\alpha+\gamma}{p a b}\right)^{\frac{b}{b-1}}-\left(\frac{\alpha}{3}+\frac{\gamma}{2}\right)\left(\frac{\alpha+\gamma}{p a b}\right)^{\frac{1}{b-1}}=28333.3
$$

The overall revenue of the supply chain is 72,000 alike in scenario 2 .

Comparing Scenario 1 and Scenario 3, the benefits of all participants in the agricultural supply chain financial model have greatly improved compared with the traditional agricultural product circulation model. Therefore, agricultural supply chain finance plays an important role in promoting agricultural development.

\section{Conclusions and Suggestions}

In this paper, the financial coordination model of agricultural supply chain is constructed, and the income distribution model of Shapley value method is introduced. The financial and economic feasibility of agricultural supply chain is then verified by numerical simulations. It showed that with the agricultural supply chain finance, the overall income of agricultural industry chain and the income of each participant improved. However, at present, China's agricultural supply chain finance has not been fully developed, and there are many constraints. Hence, joint efforts by all parties are required to create favorable conditions for the development of the agricultural supply chain finance.

Grass-roots government organizations should be entrusted to play guiding and bridging roles. For a long time, influenced by the idea of small-scale peasant economy, farmers who have low educational levels lacked the initiative to seek innovation as well as development and they were skeptical towards financial institutions. In view of this, grass-roots government organizations should guide farmers to actively participate in the trend of agricultural innovation and development. A good communication bridge between farmers, financial institutions, and agricultural enterprises should also be built so that farmers would be able to fully trust and understand the financial model of agricultural supply chain and eventually, participate in it.

By improving laws and regulations, the risk management system would also be enhanced. The financial capital chain of agricultural supply chain is complex, involving farmers, agricultural enterprises, financial institutions, and other participants. Any problems that occur to one of the participants would affect the development of the whole industrial chain. Therefore, improving the risk management mechanism as well as clarifying the rights and responsibilities of all parties will benefit in reducing the possibility of credit and ethical risks. 


\section{Disclosure statement}

The author declares no conflict of interest.

\section{References}

[1] Yang J, 2012, Exploring the financial model of agricultural supply chain. China Finance, (22): 85-86.

[2] Shao X, 2013, Innovation of agricultural supply chain financial model - taking Mawangdui vegetable wholesale market as an example. Agricultural Economic Problems, 34(08): 62-68, 111.

[3] Zou J, Li M, 2019, Research on the credit enhancement of farmers from the perspective of agricultural supply chain finance. Financial Theory and Practice, 40(06): 32-38.

[4] Ye H, 2019, Analysis of the development path of financial innovation in agricultural supply chain from the perspective of rural financial repression. Journal of Qingdao Agricultural University (Social Science Edition), 31(01): 23-28, 34.

[5] Guo J, Gu L, Yang L, 2020, Review and prospect of poverty reduction in agricultural supply chain finance in China. Journal of Beijing Jiaotong University (Social Science Edition), 19(01): 106-113.

[6] Guan X, 2011, Exploration and practice of "Agricultural Supply Chain Finance" mode-based on the investigation and analysis of agricultural industry financial innovation of Longjiang Bank. Banker, (11): 110-113, 7.

[7] Ceng L, Cheng X, Sun L, 2018, Financial model optimization and economic benefit calculation of agricultural supply chain. Accounting Monthly, (06): 160-166.

[8] Cai R, 2006, Analysis of the definition and legal status of agricultural cooperatives. Enterprise Economics, (03): 158-160.

[9] Shen Y, Li J, Yang J, 2019, Research on poverty reduction mechanism of agricultural supply chain financial credit under the background of rural revitalization - based on the perspective of poverty alleviation ability of member farmers. Journal of Southwest University (Social Science Edition), 45(02): 50-60, 196. 